JOURNAL of

MAINE MEDICAL CENTER Journal of Maine Medical Center

\title{
Qualitative Evaluation of a Certificate in Health Care Improvement for Interprofessional Teams
}

\author{
Hannah R. Martin \\ Tufts University School of Medicine
}

Et al.

Follow this and additional works at: https://knowledgeconnection.mainehealth.org/jmmc

Part of the Medicine and Health Sciences Commons

\section{Recommended Citation}

Martin, Hannah R.; Carpenter, Eilish W.; Bates, Peter W.; Graydon-Baker, Erin M.; Parker, Mark G.; Peck, Jordan S.; Rothenberg, Debra MD, PhD; Stickney, Isaac Z.; Saleh, Ghassan A.; Wennberg, John E.; Tooker, John; Trowbridge, Robert Jr; and Fairfield, Kathleen M. (2021) "Qualitative Evaluation of a Certificate in Health Care Improvement for Interprofessional Teams," Journal of Maine Medical Center. Vol. 3 : Iss. 2 , Article 15.

Available at: https://knowledgeconnection.mainehealth.org/jmmc/vol3/iss2/15 https://doi.org/10.46804/ 2641-2225.1090

The views and thoughts expressed in this manuscript belong solely to the author[s] and do not reflect the opinions of the Journal of Maine Medical Center or MaineHealth.

This Research and Quality Improvement Brief is brought to you for free and open access by Maine Medical Center Department of Medical Education. It has been accepted for inclusion in the Journal of Maine Medical Center by an authorized editor of the MaineHealth Knowledge Connection. For more information, please contact Dina McKelvy mckeld1@mmc.org.

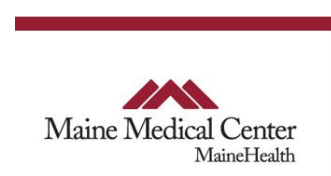




\section{Qualitative Evaluation of a Certificate in Health Care Improvement for Interprofessional Teams}

\section{Acknowledgements}

The authors are grateful for the assistance of Michael Kohut, $\mathrm{PhD}$ in development of the semi-structured interview guide and for thematic analysis guidance.

\section{Authors}

Hannah R. Martin; Eilish W. Carpenter; Peter W. Bates; Erin M. Graydon-Baker; Mark G. Parker; Jordan S.

Peck; Debra Rothenberg MD, PhD; Isaac Z. Stickney; Ghassan A. Saleh; John E. Wennberg; John Tooker; Robert Trowbridge Jr; and Kathleen M. Fairfield 


\section{Qualitative Evaluation of a Certificate in Health Care Improvement for Interprofessional Teams}

Hannah R. Martin, MD, ${ }^{1}$ Eilish W. Carpenter, BA, ${ }^{2}$ Peter W. Bates, MD, ${ }^{1}$ Erin M. Graydon-Baker, RRT, ${ }^{4}$ Mark G. Parker, MD, ${ }^{1,3,4,5}$ Jordan S Peck, PhD, , ${ }^{1,6}$ Debra A. Rothenberg, MD, PhD, ${ }^{1,7}$ Ghassan A. Saleh, DMD, MS, ${ }^{4}$ Isaac Z. Stickney, MEd, CGS, ${ }^{1,2}$ John Tooker, MD, MBA, ${ }^{2}$ Robert L. Trowbridge, MD, ${ }^{1,2,3}$ John E. Wennberg, MD, MPH, ${ }^{8}$ Kathleen M. Fairfield, MD, MPH, $\mathrm{DrPH}^{1,2,3,4}$

${ }^{1}$ Tufts University School of Medicine, Boston, MA, ${ }^{2}$ Maine Medical Center, Department of Medical Education, Portland, ME, ${ }^{3}$ Maine Medical Center, Department of Medicine, Portland, ME, ${ }^{4}$ MaineHealth, Department of Quality and Safety, Portland, ME, ${ }^{5}$ Maine Medical Center, Division of Nephrology and Transplantation, Portland, ME, ${ }^{6}$ Southern Maine Health Care, Biddeford, ME, ${ }^{7}$ Maine Medical Center, Department of Family Medicine, Portland, ME, ${ }^{8}$ The Dartmouth Institute, Lebanon, $\mathrm{NH}$

nterprofessional education, the continuing educational and professional development of patient-centered care teams, is a growing focus of medical education, particularly given the imperative to include health system science. ${ }^{1}$ Interprofessional education improves team functioning. ${ }^{2-4}$ We created the Certificate for Health Care Improvement ${ }^{5}$, hereafter referred to as the Certificate, to address gaps in improvement science knowledge and training among care teams, and to encourage teams to engage in improvement work. Four cohorts (comprising 77 total participants) have completed the program. The goals of the Certificate are to:

- Introduce improvement science methods;

- Develop interprofessional teams that include medical students; and

- Practice quality improvement, reduce health care disparities, and improve population health.

The 7-month program includes 5 modules: Learning Health Care Systems, Improvement Science, Patient Safety and Diagnostic Error, Population Health and Health Equity, and Leading Change. Each module includes key readings, brief videos, faculty-moderated discussion boards, and weekly

Correspondence: Kathleen Fairfield, MD, MPH, DrPH Co-Director, The Academy at MITE, Maine Medical Center 509 Forest Avenue, Suite 300

Portland, ME 04102

fairfk@mmc.org video-conference calls with faculty. Teams complete a longitudinal improvement project. ${ }^{5}$

The objective of this research was to provide a rigorous qualitative evaluation of the Certificate.

\section{METHODS}

An interview guide (Table 1) was constructed under the direction of a qualitative researcher. We invited $19 \%(15 / 77)$ of former participants from the first 3 years of the Certificate program (2017-2020) to be interviewed. Participants were selected to ensure representation across cohorts and roles. We completed 12 semi-structured interviews with participants, each lasting approximately 45 minutes. We interviewed 3 medical students, 1 physician leader, 2 quality engineers, 2 research coordinators, 2 project managers, 1 public health practitioner, and 1 practice leader. A medical student who previously participated in the program (HRM) and a research assistant (EWC) conducted the interviews and performed the qualitative analysis along with the program director (KMF). All interviews were recorded via the Zoom video platform (version 5.4.4) and transcribed through Zoom or Trint audio transcription software. Transcriptions were edited manually by the interviewer to remove filler words (e.g., "uh","um") and duplicate words before analysis using MAXQDA. 


\section{Table 1. Semi-structured Interview Guide}

\section{Question}

1. What is your current role? What was your role when you took the Certificate in Health Care program?

2. What do you remember about the program?

3. Why did you take the program?

4. What were you expecting when you started the program?

5. Which of your expectations were met?

6. Tell me about any expectations you had that were not met entirely?

7. Which modules within the program were most interesting to you? (Why)

8. Which modules within the program were least interesting to you? (Why)

9. Which modules have the most applicability in your current role? (Why)

10. Which modules have the least applicability in your current role? (Why)

11. Have you been involved with any improvement projects?

a. What were they, briefly?

b. In those projects, did you use any tools in that program?

12. Do you use the improvement tools in your current role (if so, which ones)?

13. Are there any other ways you have been able to use those tools outside of those quality improvement projects?

14. Have any concepts affected how you think about things? Were any of the concepts themselves useful?

15. What specific skills did you learn in the program?

16. Would you recommend the program to a peer at your institution? (Why or why not?)

17. How do you see yourself using the program material in the future (if at all)?

18. If you participated as a team, did you feel like there was a benefit for team-building?

19. To what extent did your institution or group support your participation in the program?

20. Did the program benefit your institution or group?

21. How was your experience of completing a project? How do you feel like this has impacted how you will do improvement work?

22. What are some areas of the program that could be improved?

23. What changes could be made to make the program better?

24. Reflecting back on what we've discussed and what you have done since completing the program, what did you get out of the program? 
A comprehensive code book was constructed from the interview guide. Content and thematic analyses were performed. The code book was refined iteratively, and there was thematic convergence among 12 interviews. Interviews were coded (EWC), checked (HRM), and compared with each other. Coders met after the first 2 transcripts were completed. All questions referred to the program as completed by participants, which varied slightly from year to year. Documents from the course were made available to participants before interviews; however, participants were not required to review these documents. The MaineHealth Institutional Review Board reviewed and approved this study.

\section{RESULTS}

In this study, $17 \%(2 / 12)$ of participants completed the program between 2017 and 2018, 50\% (6/12) completed the program between 2018 and 2019, and $33 \%(4 / 12)$ completed the program between 2019 and 2020. From the content analysis, 100\% $(12 / 12)$ of participants would recommend the program to a peer, $75 \%(9 / 12)$ were involved in an improvement project after completing the program, and $58 \%(7 / 12)$ were currently using the program materials. Those who participated earlier in the program (2017-2018) recalled fewer specifics about the program. At times, the participants felt frustrated with the projects, but they also appreciated the complexity of work in health care improvement. From the thematic analysis (Table 2), dominant themes of professional development and improved confidence around leading and completing future improvement projects emerged. Respondents also reported gaining new insights about health care delivery and public health, as well as specific improvement tools. Completing a team improvement project and networking with others doing similar work were also consistent themes.

\section{DISCUSSION}

All respondents would recommend this interprofessional training program for health care improvement to a peer, and most intend to participate in future improvement projects. Participants welcomed the professional development opportunity, had increased confidence about improvement work using standard tools, and gained insights into the science of health care delivery.

Our findings are similar to those of Baxley and colleagues $^{6,7}$ who created the Teachers of Quality Academy. This program trained interprofessional faculty to teach and conduct health systems science, particularly related to professional development and continuing improvement work. Stille et $\mathrm{al}^{8}$ reported increased readiness to lead improvement projects among faculty in a physicianonly program. Similarly, the Quality and Safety Educators Academy ${ }^{9}$ provides faculty development in this area, although this program requires travel. To our knowledge, our program is the first training intended to teach improvement science to interprofessional teams with embedded medical students.

Limitations of this study include the small sample size and variation in the time between program completion and interviews ( 2 months to 2 years). Selection bias may have also occurred, as participants were chosen by a research assistant (although this selection was done in an attempt to provide representation of all disciplines). We have not yet tracked outcomes from the improvement projects.

\section{CONCLUSIONS}

Development of an interprofessional training program for team-based learning focused on health care improvement resulted in an increased use of materials and intention to remain involved in improvement science. Continued refinement of the program will include additional support for longitudinal projects and evaluation of project outcomes. 
Table 2. Thematic Analysis

Theme Representative quotes

Professional

development

"they influenced permanently, ... induced a permanent change in how I have done my work since then" (engineer)

"It makes me more willing to jump into projects or if I see something that I think needs to be changed. I think my antenna's up a little bit more than before I did the course." (medical student)

\section{Confidence to} carry out future improvement projects
"Knowing that I could take part in something like this. I would be more open to another program if something came our way. I know that I could take part in it with my team, and we could do a good job. So it's knowing that we can get through, that we can do another one." (research coordinator)

"It gave me more confidence to know what l'm talking about when we do meet to improve on a process, I do have that knowledge to fall back on. It strengthened my quality improvement knowledge that I had already brought to the table" (research coordinator)

"I know for one, l'm going to be involved in improvement projects. It's in my nature. And I know that I will." (medical student)

Insight about health care delivery or public health

"I really dig that content. The variation, I think was really enlightening and upsetting. Right. I think that's disappointing. But it was something that I hadn't really read about or done any in-depth stuff about. It was that part really also kind of with the couple of things really stood out almost immediately." (public health provider)

"a lot of that master's in public health doesn't always connect in detail to research or clinical practice. And so it was kind of ... a nice bridge between the Masters and M.D." (medical student)

"I would say that it met my expectation of wanting something that would supplement my knowledge more than the master of public health." (medical student)

Specific skills and using improvement science tools
"I am so excited because it's funny a piece of paper that says your M.D. does open up a lot of opportunities for you. And I think I think Tufts does a really good job about preparing you for being an advocate and making sure that you're utilizing your skills to improve. ... And I will be routinely circling back to that folder to say, wait, how do I develop a quality improvement project... So, yes, I will use this. I will develop a quality improvement project because I think it's important." (medical student)

"It's really nice to have this background. Not like l'm going to be fluid and graded in at the beginning, but more. I can always look back at our lectures and our reading materials and be like. OK. Like, I know Lean and I know, like some of the other ones on how to kind of streamline things and I know at least where to start." (medical student) 
Table 2. (continued) Thematic Analysis

Theme Representative quotes

Specific skills and using improvement science tools
"But yeah, I would say that there's always like some of those things always in the back of my head. Absolutely. As something that's, I guess, more ForwardLooking in my case. Now looking at different positions within public health. I think a lot more about team structures and how teams tackle problems." (public health provider)

"Yeah, I think just thinking systematically about improvement science. I never thought of that before, I never had any experience in that. So I think I would definitely revisit the tools and methodology from the course." (research coordinator)

"I got a good tool kit and guide going forward to use quality improvement both in my confidence and my actual ability to create a project that is meaningful and will be done correctly." (medical student)
Improvement project experience

"I think pretty commonly you're not starting the project on your own. And maybe it is your idea and something that you are really interested in. ...And so in some ways, doing the project at that staggered start from looking at the tools might be helpful because it might be more realistic to what l'll do in the future and help me notice when things what things I need to be like, OK, we need to do this, this and this before we move any further. That that's doing this project with the course definitely showed me." (medical student)

“...have that under my belt... it definitely arms me when I go to the table if we're doing some kind of improvement work." (research coordinator)

Team building/

"The more contact with your team, the better for building camaraderie, networking especially if you don't know all of the players...It's really cool to see what they take away from the content and how they think, it can really give a lot of insight." (research coordinator)

"I didn't have a problem not having a team because I felt like I was still involved. I felt like I was still doing something and learning from it." (medical student)

"And beyond that, the networking aspect of the health care certificate course, if it's connecting with me, with people that I will that I still work with today and I will continue to work with in a further capacity." (medical student) 


\section{Acknowledgements:}

The authors are grateful for the assistance of Michael Kohut, PhD in development of the semistructured interview guide and for thematic analysis guidance.

Keywords: improvement science, interprofessional education, quality, patient safety, qualitative analysis

\section{Conflicts of Interest: None}

\section{REFERENCES}

1. Skochelak SE, Stack SJ. Creating the medical schools of the future. Acad Med. 2017;92(1):16-19. doi:10.1097/ ACM.0000000000001160

2. Gordon PR, Carlson L, Chessman A, Kundrat ML, Morahan PS, Headrick LA. A multisite collaborative for the development of interdisciplinary education in continuous improvement for health professions students. Acad Med. 1996;71(9):973-978. doi:10.1097/00001888-199609000-00012

3. Headrick LA, Knapp M, Neuhauser D, et al. Working from upstream to improve health care: the IHI interdisciplinary professional education collaborative. Jt Comm J Qual Improv. 1996;22(3):149-164. doi:10.1016/s1070-3241(16)30217-6

4. Wilkes M, Kennedy R. Interprofessional health sciences education: it's time to overcome barriers and excuses. $J$ Gen Intern Med. 2017;32(8):858-859. doi:10.1007/s11606-0174069-z

5. Fairfield KM, Martin HR, Bates PW, et al. Development of a Certificate in Health Care Improvement for inter-professional teams. JMMC. 2020;2(2). Accessed February 25, 2021. https:// knowledgeconnection.mainehealth.org/cgi/viewcontent. cgi $?$ article $=1059 \&$ context $=$ jmmc

6. Baxley EG, Lawson L, Garrison HG, et al. The Teachers of Quality Academy: A Learning Community Approach to Preparing Faculty to Teach Health Systems Science. Acad Med. 2016;91(12):1655-1660. doi: 10.1097/ACM.0000000000001262

7. Walsh DS, Lazorick S, Lawson L, et al. The Teachers of Quality Academy: evaluation of the effectiveness and impact of a health systems science training program. Am JMed Qual. 2019;34(1):3644. doi: $10.1177 / 1062860618778124$

8. Stille CJ, Savageau JA, McBride J, Alper EJ. Quality improvement "201": context-relevant quality improvement leadership training for the busy clinician-educator. Am J Med Qual. 2012;27(2):98105. doi: 10.1177/1062860611414404

9. Myers JS, Tess A, Glasheen JJ, et al. The Quality and Safety Educators Academy: fulfilling an unmet need for faculty development. Am J Med Qual. 2014;29(1):5-12. doi:10.1177/1062860613484082 